\title{
Gastric Myeloid Sarcoma
}

\author{
Pedro Marcos ${ }^{\mathrm{a}}$ Catarina Atalaia-Martins ${ }^{\mathrm{a}}$ Sandra Barbeiro ${ }^{\mathrm{a}}$ \\ Maria Fernanda-Cunha ${ }^{b}$ Liliana Elise $^{a}$ Helena Vasconcelos $^{a}$ \\ ${ }^{a}$ Gastroenterology Department, Centro Hospitalar de Leiria, Leiria, Portugal; \\ bPathology Department, Centro Hospitalar de Leiria, Leiria, Portugal
}

\section{Keywords}

Myeloid sarcoma . Acute myeloid leukemia . Stomach .

Endoscopy

\section{Sarcoma mieloide gástrico}

\section{Palavras Chave}

Sarcoma mieloide - Leucemia mieloide aguda .

Estômago · Endoscopia

A 64-year-old man was admitted with severe, symptomatic microcytic anemia. There was no visible blood loss, but the patient had noticed significant weight loss and increasing asthenia in the preceding 2 months. $\mathrm{He}$ had a past medical history of compensated alcoholic liver cirrhosis with portal hypertension. His family history was unremarkable. Admission laboratory examination revealed anemia (hemoglobin $7.2 \mathrm{~g} / \mathrm{dL}$ ), mild thrombocytopenia (chronic, secondary to hypersplenism), normal white blood cell count, and iron deficiency. Esophagogastroduodenoscopy revealed an extensive, ulcerated neoplasm with a central yellow hue occupying the entire posterior wall of the gastric antrum without any signs of active or recent bleeding (Fig. 1). Endoscopic biopsies revealed an undifferentiated proliferation of malignant

\section{KARGER}

E-Mail karger@karger.com www.karger.com/pjg
(C) 2019 Sociedade Portuguesa de Gastrenterologia

Published by S. Karger AG, Basel

Karcer

Open access

This article is licensed under the Creative Commons AttributionNonCommercial-NoDerivatives 4.0 International License (CC BYNC-ND) (http://www.karger.com/Services/OpenAccessLicense) Usage and distribution for commercial purposes as well as any distribution of modified material requires written permission. blast cells arranged in cohesive nests and single files, which disrupted the underlying gastric tissue architecture (Fig. 2). Immunohistochemistry was positive for CD43, CD117, and vimentin but negative for cytokeratins (AE1/ AE3 and MNF116), chromogranin A, NSE, S100, HMB45, Melan A, CD29, CD79a, CD3, CD5, BCL6, CD30, CD10, TdT, CD34, CD56, and myeloperoxidase (Fig. 3). More than $70 \%$ of the cells were Ki-67 positive. These histological and immunostaining findings indicated gastric myeloid sarcoma. Computed tomography did not reveal any lesions in other organs. The peripheral blood smear and a bone marrow biopsy excluded leukemia. BCR$A B L 1$ fusion gene transcripts were not detected. Based on these findings, a diagnosis of isolated gastric myeloid sarcoma was established, and chemotherapy was initiated. However, despite best care, the patient developed tumor lysis syndrome early in the treatment, resulting in multiorgan failure, and he died after a few days.

Myeloid sarcoma is characterized by the extramedullary proliferation of myeloid blasts, which effaces the normal tissue architecture of the involved organ [1]. This uncommon condition mostly occurs in patients with a past or current history of acute myeloid leukemia (AML), myeloproliferative neoplasm, or myelodysplastic syndrome. However, in rare cases (as in the present case), myeloid sarcoma may develop as a solitary lesion without associated leukemia $[1,2]$. Because myeloid sarcoma can occur 
Fig. 1. Endoscopic images of the ulcerated neoplasm in the gastric antrum.
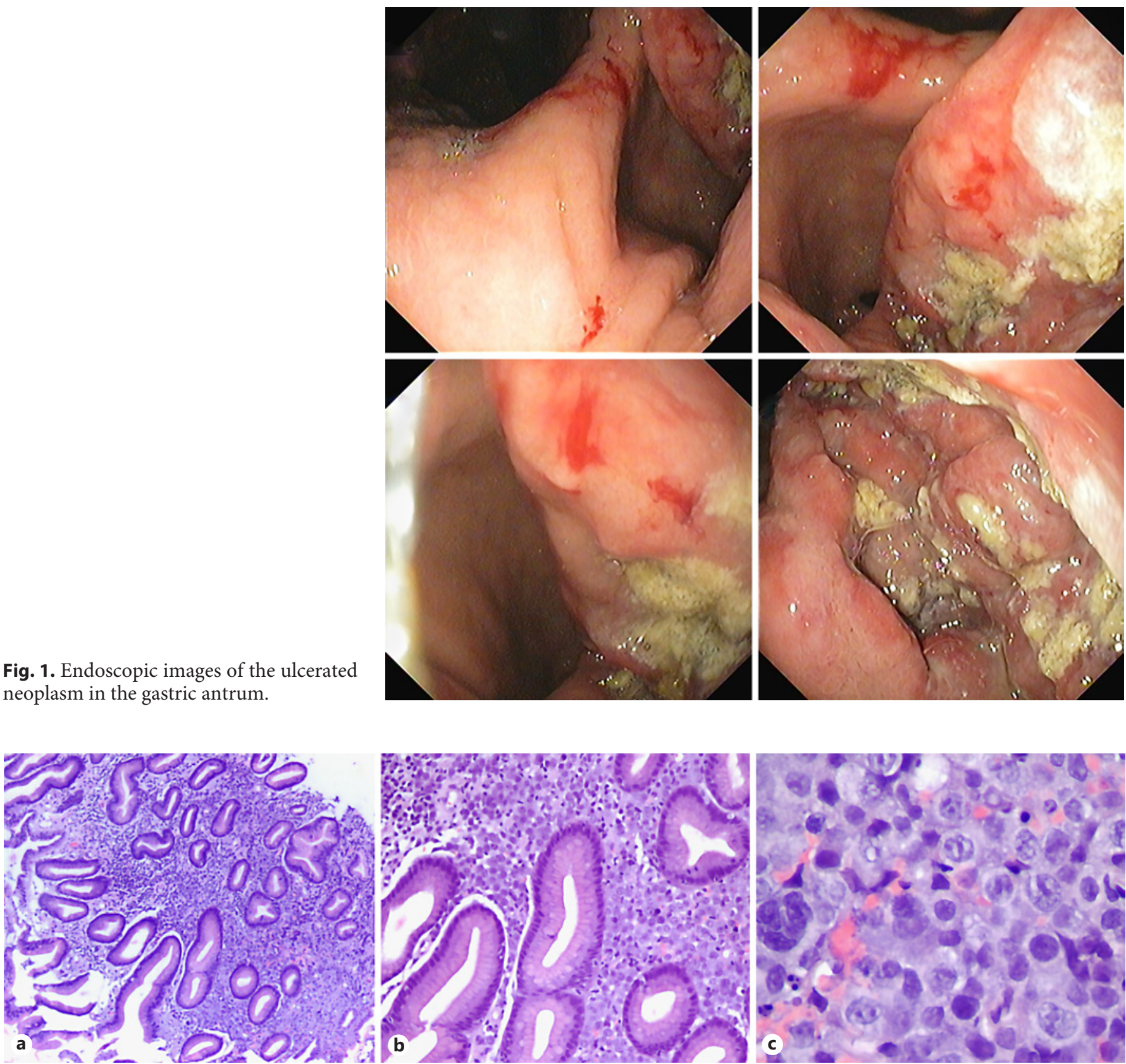

Fig. 2. Histology of gastric myeloid sarcoma. a Diffuse proliferation of immature cells (myeloblasts) that disrupt the gastric wall architecture. Hematoxylin and eosin $(\mathrm{HE}) . \times 40 . \mathbf{b}$ Myeloblasts arranged predominantly in single files or nests. HE. $\times 100$. c Medium- and large-sized immature cells with heterogeneous cytoplasm, pleomorphic nucleus, finely dispersed chromatin, prominent nucleoli, and mitoses. HE. $\times 400$.

at any age and in any organ, its clinical manifestations are diverse [3]. Although approximately $10 \%$ of myeloid sarcomas occur in the gastrointestinal tract, stomach involvement remains exceedingly rare [4]. The endoscopic features of gastric myeloid sarcoma range from near-normal mucosa to elevated ulcers or mass lesions [5]. Al- though the diagnosis of myeloid sarcoma in patients with AML is usually straightforward, the diagnosis of an isolated myeloid sarcoma (nonleukemic) can be challenging [1-3]. Histopathology and immunohistochemistry findings are key in establishing the diagnosis. Myeloid sarcoma should be considered in the differential diagnosis of 

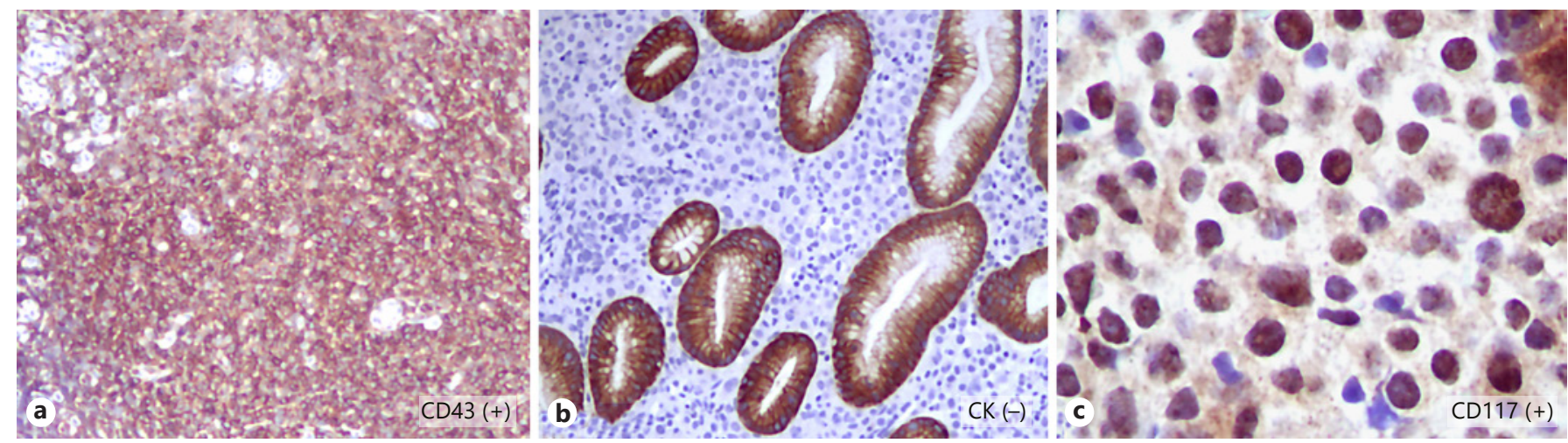

Fig. 3. Immunohistochemistry of gastric myeloid sarcoma cells. a CD43+. b Cytokeratin-. c CD117+.

an atypical cellular infiltrate regardless of the site [2]. Extensive immunohistochemical panels must be used; otherwise, differentiating these lesions from tumors such as lymphoma may be extremely difficult [2-4]. The prognosis of myeloid sarcoma is generally poor. Without treatment, most patients succumb to the disease within a short space of time after diagnosis [2,3]. Systemic chemotherapy remains the mainstay of treatment even for isolated myeloid sarcomas because most patients progress to AML $[2,3]$. Radiotherapy and/or surgery are usually reserved to treat residual lesions or reduce the mass effect of a symptomatic myeloid sarcoma [2,3].

In summary, gastric myeloid sarcoma is exceedingly rare, particularly in the absence of AML. This condition constitutes a diagnostic challenge, mostly in terms of histopathology. Careful differentiation from similar-appearing entities has important implications for treatment. The use of a wide antibody panel is crucial for establishing an early and accurate diagnosis.

\section{Statement of Ethics}

This study did not require informed consent or review/approval by the appropriate ethics committee.

\section{Disclosure Statement}

The authors have no conflicts of interest to declare.

Funding Sources

The authors have no funding sources to declare.

\section{Author Contributions}

Pedro Marcos reviewed the literature and drafted the manuscript. Catarina Atalaia-Martins and Sandra Barbeiro reviewed the manuscript. Maria Fernanda-Cunha provided the pathology images and reviewed the manuscript. Liliana Eliseu and Helena Vasconcelos reviewed the manuscript and approved the final version.
References

Myeloid Sarcoma
1 Arber DA, Orazi A, Hasserjian R, Thiele J, Borowitz MJ, Le Beau MM, et al. The 2016 revision to the World Health Organization classification of myeloid neoplasms and acute leukemia. Blood. 2016 May;127(20):2391405.

2 Almond LM, Charalampakis M, Ford SJ, Gourevitch D, Desai A. Myeloid Sarcoma: Presentation, Diagnosis, and Treatment. Clin Lymphoma Myeloma Leuk. 2017 May;17(5): 263-7.

3 Magdy M, Abdel Karim N, Eldessouki I, Gaber O, Rahouma M, Ghareeb M. Myeloid Sarcoma. Oncol Res Treat. 2019;42(4):224-9.
4 Goyal G, Bartley AC, Patnaik MM, Litzow MR, Al-Kali A, Go RS. Clinical features and outcomes of extramedullary myeloid sarcoma in the United States: analysis using a national data set. Blood Cancer J. 2017 Aug;7(8):e592.

5 Sekaran A, Darisetty S, Lakhtakia S, Ramchandani M, Reddy DN. Granulocytic Sarcoma of the Stomach Presenting as Dysphagia during Pregnancy. Case Rep Gastrointest Med. 2011;2011:627549. 